\title{
Reconhecimento e progresso moral: aportes da concepção de modernidade de Honneth para a ideia de formação humana
}

\author{
Angelo Vitório Cenci \\ Universidade de Passo Fundo
}

\section{Resumo}

0 presente texto tematiza a concepção de progresso moral presente na teoria do reconhecimento honnethiana visando a extrair dela aportes à ideia de formação humana. Para dar conta de tal intento, procura-se mostrar em que sentido ocorre, com a modernidade, uma evolução em cada uma das esferas do reconhecimento e como tal evolução pode ser lida como progresso moral. Esse passo ajuda a explicitar, então, os princípios que dão sustentação à ideia de progresso moral para, por fim, situar, à luz da teoria do reconhecimento de Honneth, alguns questionamentos e indicativos para a formação humana a partir do contraste entre os conceitos de progresso moral e de contradições paradoxais.

Palavras-chave:Progressomoral. Reconhecimento. Modernidade.Contradições paradoxais. Formação. 


\section{Recognition and moral progress: contributions from Honneth's concept of modernity to the conception of human development}

This paper addresses the conception of moral progress in Honneth's theory of recognition in order to derive from it contributions towards the conception of human development. In order to meet such goal, efforts are made so as to show in what sense there has been, along modernity, an evolution in each sphere of recognition and how such an evolution can be understood as moral progress. This step thus helps make explicit the principles that support the notion of moral progress to finally establish, according to Honneth's theory of recognition, some questions and indicators for human development from the contrast between the concepts of moral progress and paradoxical contradictions.

Keywords: Moral progress. Recognition. Modernity. Paradoxical contradictions. Development.

\section{Reconocimiento y progreso moral: contribuciones de la concepción de modernidad de Honneth para la idea de formación humana}

En este trabajo se estudia la concepción del progreso moral presente en la teoría del reconocimiento honnethiana buscando extraer de ella contribuciones para la idea de formación humana. Para hacer realidad esa intención, se busca mostrar de qué manera ocurre, con la modernidad, una evolución en cada una de las esferas del reconocimiento y cómo tal evolución puede ser leída como progreso moral. Ese paso ayuda a explicar, entonces, los principios que apoyan la idea de progreso moral para, al final, situar, bajo la luz de la teoría del reconocimiento de Honneth, algunas cuestiones e indicativos para la formación humana, a partir del contraste entre los conceptos de progreso moral y de contradicciones paradójicas.

Palabras-clave: Progreso moral. Reconocimiento. Modernidad. Contradicciones paradójicas. Formación. 


\section{Posição do problema}

Honneth desenvolve uma concepção de progresso moral sem recorrer a uma filosofia da história, de cunho teleológico, como o fizeram antes Kant e Hegel. ${ }^{1}$ Tal concepção aparece já, em 1992, em "Luta por reconhecimento", a partir de diferentes dimensões de sua teoria do reconhecimento. A primeira de tais dimensões decorre do fato de o autor apropriar-se de aspectos da obra de Mead com o intuito de transformar as intuições de Hegel mediante uma base empírica e materialista. Honneth empreende, em tal obra, uma reconstrução sistemática do pensamento do jovem Hegel vinculando o conceito de reconhecimento deste à psicologia social de Mead e entende poder, com esse recurso, superar a conotação metafísica e idealista que esse conceito possuía em Hegel. Todavia, mantém de Hegel a ideia de luta por reconhecimento entendida como uma relação dialética que implica um constante aprendizado entre os sujeitos no que diz respeito às suas próprias identidades.

Vale-se também de ideias dos teóricos da história social, como Edward Thompson e Barrington Moore, para sustentar a tese de que as lutas por reconhecimento podem ser compreendidas como o processo histórico do progresso moral de uma sociedade. Interessa-lhe, particularmente, a categoria de economia moral de Thompson e o conceito de contrato social implícito de Moore para mostrar que os acontecimentos históricos indicam uma démarche de desenvolvimento moral. A luta por reconhecimento aparece, então, como impulsionadora do progresso moral na medida em que oferece possibilidades para ampliar as formas de reconhecimento historicamente constituídas. A luta é compreendida como um processo formativo tanto no plano individual quanto no social e ocorre mediante o conflito impulsionado pela expectativa de ampliação das relações de reconhecimento.

A ideia de progresso moral pode ser encontrada, ainda, associada ao conceito de vida boa baseada numa relação ética entre os indivíduos com vistas à autorrealização. Sob esse prisma, a concepção de vida boa, vinculada a uma concepção formal de eticidade, constitui-se no horizonte normativo que possibilita tal progresso. A ideia de autorrealização demanda a possibilidade de uma realização dos objetivos de vida livremente escolhidos pelos sujeitos e só pode ser efetivada por eles quando puderem chegar a uma autorrelação prática que thes permita serem reconhecidos em três esferas - a amorosa, a jurídica e a social - que vinculam, respectivamente, o desenvolvimento de três tipos de autorrelação

1. Antes de Honneth, Habermas, já na década de 70 , amparado em Weber e Piaget, rumara claramente nessa direção ao substituir a filosofia da história por uma teoria da evolução social. A esse respeito ver Sgró (2007, p. 108s.). Em Habermas, a evolução social é referida a estruturas universais da consciência e a níveis de aprendizagem ordenados de acordo com uma lógica do desenvolvimento (1990, p.166). Habermas mantém a ideia de progresso, todavia a evolução social não é entendida mais como um macroprocesso que se realiza num sujeito humano-genérico. Os portadores da evolução social passam a ser a sociedade e os sujeitos integrados nela e a evolução desenvolve-se de acordo com o modelo de uma hierarquia de estruturas cada vez mais abrangentes de caráter antropológico, motivacional e cognitivo. (1990, p. 206) 
prática, a saber: a autoconfiança, o autorrespeito e a autoestima. ${ }^{2}$

Por fim, a ideia de progresso moral aparece articulada a uma concepção de modernidade que está diretamente relacionada ao desenvolvimento das diferentes esferas de reconhecimento recíproco. Em Honneth, a modernidade é identificada com as profundas transformações que as esferas de reconhecimento vão sofrendo internamente, impulsionadas pelas expectativas normativas de reconhecimento recíproco alimentadas entre os sujeitos. Essas expectativas, oriundas de um contexto prévio de relações de reconhecimento, são intrínsecas à infraestrutura da vida social e a sua lesão pode levar à luta por reconhecimento em diferentes níveis, tais como o do amor/amizade, do direito e da estima social. Como se sabe, Honneth (2003) situa o conflito na base da interação humana e este é fator de progressos tanto no plano social quanto no individual. A luta por reconhecimento possui um sentido moral por visar dar conta de experiências de desrespeito que afetam a identidade pessoal ou coletiva e impulsiona os sujeitos à ação para restaurar ou desenvolver relações de reconhecimento que atendam as suas expectativas. E é justamente a negação das expectativas de reconhecimento o fator que pode impulsionar o desenvolvimento de tais relações a elevarem-se a um plano mais evoluído que as existentes. (Nobre, 2003)

0 presente texto possui o intuito de tematizar a concepção de progresso moral presente na teoria do reconhecimento honnethiana visando a extrair dela aportes à ideia de formação humana. Tal concepção assume uma feição pós-metafísica e a sua importância concerne, sobretudo, à possibilidade de ampliação tanto da autorrelação prática do sujeito (subjetividade) quanto das esferas sociais de reconhecimento. Nesse sentido, na obra de Honneth, ela é indissociável de uma concepção da modernidade entendida como diferenciação das esferas de reconhecimento. Para dar conta de tal intento, procura-se, após o posicionamento do problema (1), mostrar em que sentido ocorre, com a modernidade, uma evolução em cada uma das esferas do reconhecimento e como tal evolução pode ser lida como progresso moral (2). Em seguida, pretende-se explicitar os princípios que dão sustentação à ideia de progresso moral (3). Por fim, trata-se de situar alguns questionamentos e indicativos para a formação humana a partir do contraste entre os conceitos de progresso moral e de contradições paradoxais, num esforço de fazer jus à genuína intenção, própria a todo modelo de teoria social crítica, de encontrar inscritas já, no próprio diagnóstico do real, perspectivas emancipatórias (4).

2. A respeito dos padrões de reconhecimento recíproco e as correspondentes formas de autorrelação prática, vide Honneth (2003, p. 155-211). 


\section{A modernidade como resultado da diferenciação das esferas do reconhecimento recíproco}

Honneth interpreta a sociedade moderna como uma ordem institucionalizada resultante da diferenciação de três esferas sociais de reconhecimento que foram, progressivamente, autonomizando-se e evoluindo internamente. A passagem da sociedade tradicional para a moderna é entendida por ele como um processo de transformação estrutural ocorrida internamente às diferentes esferas de reconhecimento. A sociedade moderna resulta, pois, de um processo evolutivo e a sua ordem moral articula-se como uma estrutura de relações de reconhecimento. Para Honneth, os seres humanos possuem uma dependência tipicamente humana do reconhecimento intersubjetivo que se configura pelo modo particular como se institucionaliza a concessão mútua do reconhecimento numa determinada sociedade. A sua tese fundamental, em "Luta por reconhecimento", é que "a reprodução da vida social se efetua sob o imperativo de um reconhecimento recíproco porque os sujeitos só podem chegar a uma autorrelação prática quando aprendem a se conceber, da perspectiva normativa de seus parceiros de interação, como seus destinatários sociais". (Honneth, 2003, p. 155)

Essa capacidade do sujeito de assegurar-se de sua autorrelação prática, assim como as expectativas de reconhecimento intersubjetivo, amplia-se com a progressiva diferenciação das esferas de reconhecimento. Nesse sentido, na modernidade, o amor configura-se como a esfera afetiva originada com o fim das amarras do status nas relações sociais medievais e é o núcleo fundamental de toda a moralidade em razão de que esse tipo de reconhecimento é o que possibilita, na criança, o desenvolvimento de uma relação positiva para si, associada ao surgimento da autoconfiança. 0 direito moderno decorre do discurso burguês acerca da igual dignidade entre os seres humanos e possibilita o autorrespeito, base da autonomia necessária para a participação na vida pública. A estima social, por sua vez, origina-se a partir de uma mudança ocorrida em relação ao status medieval, ancorado na linhagem ou no papel social, de modo que, em sentido moderno, os sujeitos passam a ser avaliados por suas realizações com base em relações sociais simétricas de estima entre indivíduos autônomos, o que possibilita a autorrealização.

Honneth compreende essa diferenciação das esferas de reconhecimento, resultante do desenvolvimento social e moral da sociedade moderna burguesa capitalista, como o resultado de processos conflitivos que estabeleceram três formas distintas de relações sociais. Esse desenvolvimento implicou um novo tipo de relação do indivíduo consigo mesmo na medida em que é levado a aprender a referir a si mesmo por meio de três atitudes. Nas relações íntimas, marcadas por práticas de afeto e preocupação mútuos, torna-se capaz de compreender-se como um indivíduo que possui as suas próprias necessidades; nas relações jurídicas, 
que se desenvolvem segundo o modelo de igualdade de direitos e obrigações mutuamente outorgados, aprende a compreender-se como pessoa jurídica, à qual é devida a mesma autonomia que aos demais membros da sociedade; por fim, nas relações sociais, aprende a compreender-se como sujeito que possui habilidades e talentos valiosos para a sociedade (2003b). Em síntese, em sentido moderno, o indivíduo requer reconhecimento como (a) sujeito singular de necessidade (amor), (b) pessoa jurídica autônoma (direito) e (c) membro cooperativo da sociedade (estima social). Vale salientar que, assim como ocorria em Hegel, esses três tipos de atitude possuem um sentido claramente formativo para o sujeito.

Honneth entende ainda que a autocompreensão do sujeito moderno, calcada nessas três dimensões, não exclui a possibilidade de existir outras formas de relações sociais que permitam às pessoas outros tipos de relações para consigo próprias, como o caso do anonimato nas grandes cidades. ${ }^{3}$ Por sua vez, cada uma das três formas de autorrelação prática e de relações sociais distinguese por princípios normativos internos que estabelecem diferentes formas de reconhecimento mútuo e podem indicar a necessidade de ampliá-las. Assim,

[...] o 'amor' (a ideia central das relações íntimas), o princípio de igualdade la norma das relações jurídicas) e o princípio do êxito (a norma da hierarquia social) representam perspectivas normativas que possibilitam aos sujeitos arguir razoavelmente quando formas vigentes de reconhecimento são inadequadas ou insuficientes e se faz necessário ampliá-las. (Honneth, 2003b, p. 143)

Todavia, as três esferas de reconhecimento são modelos de interação que não podem ser praticadas e ampliadas se seus princípios subjacentes, anteriormente mencionados, não forem respeitados de algum modo.

Outro aspecto importante a esse respeito é que a diferenciação institucional das três esferas de reconhecimento possibilita uma maior individualidade e esta é concebida como "possibilidade de assegurar cada vez mais a singularidade da própria personalidade num contexto de aprovação social” (Honneth, 2003b, p. 143). Nesse aspecto, com cada esfera de reconhecimento mútuo que surge ou que se amplia revela novos aspectos da subjetividade humana que podem ser atribuídos positivamente a si mesmos pelos indivíduos de maneira intersubjetiva. Como já se referiu, o avanço em termos de reconhecimento recíproco implica a ampliação tanto das esferas de reconhecimento quanto das possibilidades da autorrelação prática do sujeito consigo mesmo. Tal avanço possui um sentido social e moral e representa também um ganho em termos de individuação, o que justifica que a evolução, no âmbito das esferas de reconhecimento, seja lida como progresso moral. Em suma, os princípios do amor, da igualdade e do mérito, referidos, respectivamente, a cada uma das esferas de reconhecimento, estão na base da

3. Esse aspecto lembra, evidentemente, Simmel (2007). 
infraestrutura normativa da sociedade configurada a partir da modernidade a qual se encontra sempre aberta a novos desenvolvimentos no âmbito individual e coletivo.

Amparado na moldura hegeliana da ideia de reconhecimento, Honneth vai identificar, na estrutura das relações intersubjetivas de reconhecimento, um potencial evolutivo que pode ser notado, sobretudo, na capacidade de generalização e materialização presentes nas relações jurídicas e de individuação e igualização contidas na comunidade de valores (esfera social). Também o reconhecimento amoroso possui um potencial para o desenvolvimento normativo. ${ }^{4}$ Esse potencial desenvolveu-se de modo implícito até a infância constituir-se numa fase que passa a requerer proteção especial via a tomada de consciência das obrigações especiais requerida dos adultos. 0 reconhecimento amoroso possibilita que os indivíduos adquiram confiança no valor de suas próprias necessidades corporais e é-lhe vinculado também o processo de independização, pelo qual passa o amor matrimonial burguês. Essa independização resulta do fato de as relações entre os sexos terem se liberado, aos poucos, das pressões econômicas e sociais, de modo a abrir espaço ao sentimento de afeto mútuo. (Honneth, 2003b, p. 139)

0 reconhecimento jurídico, por sua vez, foi extremamente importante para a aparição das instituições fundamentais da sociedade moderna, uma vez que colocou as bases de sua ordem moral. Ele evidenciou o estatuto do sujeito como membro da sociedade protegido por determinados direitos e separou-se da estima social, até então entendida como honra ou status, o que fez com que o indivíduo passasse a desfrutar da igualdade jurídica em relação a todos os demais semelhantes. Com a institucionalização da igualdade jurídica, o princípio da honra dá lugar à postura independente do indivíduo em relação à origem e à propriedade. $\mathrm{Na}$ modernidade, o reconhecimento jurídico toma como base as capacidades individuais dos sujeitos, e não mais a sua posição social. Os sujeitos de direito são, agora, capazes de reconhecerem-se como pessoas autônomas, em condições de decidir racionalmente a respeito de normas morais. Com a modernidade, a noção pré-moderna de honra é substituída pelo êxito pessoal e é cindida, pois,

[...] uma parte da honra assegurada pela hierarquia se democratizava, em certo sentido, outorgando a todos os membros da sociedade um igual respeito por sua dignidade e autonomia como pessoas jurídicas, enquanto a outra parte ficava, em certo sentido, 'meritocratizada': cada um desfrutaria da estima social de acordo com sua realização enquanto 'cidadão produtivo'. (2003b, p. 141 - grifos de Honneth)

Além disso, o sistema jurídico, agora, não pode mais atribuir exceções e privilégios às pessoas em função do status que estas possuem. Os privilégios e as exceções devem ser superados de modo que o direito leve em conta os interesses

4. Em "Redistribution or Recognition", Honneth (2003b, p.144, nota 35) corrige sua postura anterior de "Luta por reconhecimento" a esse respeito (2003, p. 276). 
de todos os sujeitos.

A estima social, por sua vez, configura-se como forma de reconhecimento em sentido moderno somente na medida em que ultrapassa o padrão estamental das sociedades tradicionais que orientavam a reputação dos indivíduos pela honra social (Honneth, 2003). Em tais sociedades, pautadas pela eticidade convencional, o termo "honra" expressa o grau de reputação social que um indivíduo é capaz de adquirir quando consegue cumprir as expectativas coletivas de comportamento vinculadas ao status social. Com o advento da modernidade, a ordem hierárquica da estima social passa por uma mudança estrutural. A compreensão da ordem social de valores deixa de dar-se mediante um sistema referencial objetivo e tal ordem perde tanto o fundamento metafísico de sua validade quanto a capacidade de normatizar o comportamento e, pois, também de determinar a escala de prestígio social. 0 sujeito converte-se numa grandeza biograficamente individuada. Parte considerável do que os princípios de honra asseguravam ao indivíduo migra para o âmbito da relação jurídica, alcançando validade com o conceito de dignidade humana. Porém, tal âmbito não é capaz de recolher todas as dimensões da estima social. Ocorre que, para sentir-se valiosa, a pessoa necessita ser reconhecida em realizações que ela não partilha de modo indistinto com todos os demais sujeitos. 0 conceito de honra é deslocado para a esfera privada, dando, gradativamente, lugar ao de prestígio social. As noções de prestígio ou reputação passam a indicar a medida de estima que o indivíduo goza socialmente, mas no que se refere a suas realizações e capacidades individuais. Em termos da nova forma que a estima social assume como padrão de reconhecimento, tem-se um duplo processo em relação ao conceito de honra: a sua universalização até tornar-se dignidade e a sua privatização até tornar-se integridade subjetivamente reconhecida.

\section{Progresso moral como ampliação da socialização e da inclusão social}

Conforme se viu, Honneth concebe as sociedades capitalistas liberais modernas como resultado de um processo de diferenciação e de evolução de esferas de reconhecimento. Com o desenvolvimento de tais esferas, aumentam as oportunidades de todos os sujeitos para alcançar um grau superior de individualidade, uma vez que podem experimentar mais e novos aspectos de suas próprias personalidades. A partir desse resultado, o autor introduz dois critérios para justificar o conceito de progresso nas relações de reconhecimento, a saber, o de socialização e o de inclusão. Por um lado, ocorre um processo de individuação que propicia a

[...] ]ampliação de oportunidades paraarticular legitimamentepartes da própria personalidade; por outro, vemos um processo de inclusão social, isto é, expandindo a inclusão de sujeitos no círculo dos membros plenos da sociedade. (Honneth, 2003b, p. 184-5) 
Honneth necessita estabelecer um parâmetro para distinguir desenvolvimentos históricos que possuem caráter de progresso moral daqueles que podem significar retrocesso. Esse parâmetro é encontrado nos critérios de socialização e de inclusão, pois, a seu juízo, a integração social pode melhorar mediante a individuação e a inclusão dos indivíduos. Em outros termos, o avanço representado pela sociedade moderna - o progresso nas condições do reconhecimento social - pode ser entendido como progresso moral, uma vez que a diferenciação das três esferas de reconhecimento foi acompanhada pelo incremento de possibilidades de individuação e de inclusão social. Portanto, para haver progresso nas condições do reconhecimento social

[...] ou novas partes da personalidade são abertas ao reconhecimento mútuo, de maneira que aumente o grau de individualidade socialmente confirmada; ou mais pessoas são incluídas nas relações de reconhecimento existentes, de maneira que aumente o círculo dos sujeitos que se reconhecem. (Honneth, 2003b, p. 186)

Decisivo para essa melhora qualitativa foi o fato de que, com a separação entre reconhecimento jurídico e estima social, ganhou relevância a ideia de que “.... todos os sujeitos devem ter a mesma oportunidade de autorrealização individual mediante a participação em relações de reconhecimento." (Honneth, 2003b, p. 185)

Esses dois critérios para a avaliação do progresso moral nas sociedades modernas podem ser vistos como a face positiva do núcleo ético que Honneth localizara, em consonância com toda a tradição da teoria crítica anterior, na falta de racionalidade que permeia tais sociedades e que lesa as condições de autorrealização dos sujeitos. ${ }^{5}$ Para Honneth, a ideia ética de Hegel, o seu universal racional, é a de que as patologias sociais devem ser entendidas como "o resultado de uma incapacidade das sociedades de expressar o potencial racional já inerente à suas instituições, práticas e rotinas quotidianas" (2006a, p. 106-7). Hegel vinculou progresso histórico à ética, uma vez que, para ele, a razão desdobra-se de modo a criar, em cada etapa de seu desenvolvimento, instituições éticas cujo respeito a elas e ao indivíduo permite aos sujeitos projetarem as suas vidas em direção a metas socialmente reconhecidas. A tese formulada, a partir desse tipo de diagnóstico, é que "uma forma bem sucedida de sociedade só é possível se as normas de racionalidade mais desenvolvidas forem mantidas". (Honneth, 2006a, p. 107)

Na base das formulações de tal diagnóstico de época, está o pressuposto éticonormativo da autorrealização cooperativa:

5. Honneth (2006a) observa que os autores vinculados ao instituto de pesquisa social - como Adorno, Horkheimer e Marcuse, entre outros - entenderam que tal estado de negatividade não é medido pela lesão de princípios de justiça social, mas pelo sentido mais amplo de lesão das condições da vida boa ou bem sucedida, ou seja, de patologias sociais. 
Dos membros de uma sociedade deve se poder dizer que podem levar em comum uma vida exitosa, não distorcida, se todos eles se orientarem em função de princípios ou instituições que possam ser compreendidas por eles próprios como metas racionais de sua autorrealização. (Honneth, 2006a, p.107)

Por conseguinte, na ideia do universal racional, está contido um conceito de bem comum que demanda um acordo racional entre os membros da sociedade para que as suas liberdades possam ser relacionadas cooperativamente. Isso significa que a socialização dos seres humanos só pode ser exitosa se levada adiante sob as condições de uma liberdade cooperativa. Nesse sentido, a teoria do reconhecimento de Honneth vincula a ideia de um aperfeiçoamento ético singular, pois

[...] a finalidade normativa das sociedades deveria consistir em tornar a autorrealização mutuamente possível, mas ela [teoria do reconhecimento] concebe a recomendação em vista de realizar esse objetivo como o resultado fundamentado de uma análise específica do processo de formação do ser humano. (2006a, p. 113)

É justamente essa ideia de formação do ser humano, presente no núcleo ético da teoria crítica, que permite diagnosticar a falta de racionalidade social que lesa as condições de socialização moral e, portanto, em sentido mais amplo, de autorrealização dos sujeitos.

Se o ponto de partida da teoria social crítica é localizado a partir de um estado de negatividade social, aqui o autor abre perspectivas para o que seria a outra dimensão de tal núcleo, o seu contraponto emancipatório mediante a ideia de progresso moral. Honneth observa, agora, que os parâmetros para essa ideia têm de ser definidos em relação aos três princípios do reconhecimento e o seu significado é indicado em dois passos, a saber, (a) mediante o conceito de excedente de validez, presente nas três esferas de reconhecimento; (b) por meio do exame das linhas de demarcação de tais esferas.

(a) Para Honenth, cada uma das esferas e de seus respectivos princípios de reconhecimento possuem um excedente específico de validez e o significado normativo de tal excedente expressa-se mediante a busca da adequada interpretação e aplicação deste. Dentro de cada esfera, é possível estabelecer uma dialética moral do geral e do particular em movimento. Assim, pode ocorrer de existir fatos concretos, até o presente, desconsiderados, cuja consideração moral demandaria a expansão das esferas de reconhecimento. 0 excedente normativo de validez presente em cada um dos três princípios de reconhecimento permite apelar para diferenças ou situações ainda não consideradas, como no caso da ampliação dos direitos subjetivos fundamentais. Todavia, de acordo com a concepção de progresso moral aqui explicitada, no plano normativo, só podem ser consideradas como fundadas aquelas demandas individuais ou sociais que atendam a duas 
exigências. Trata-se das demandas que contribuem potencialmente para a efetiva expansão das relações sociais de reconhecimento e que apontem na direção de um incremento do nível moral de integração social (Honneth, 2003b, p. 187). Os critérios de individuação e de inclusão são os parâmetros para tal.

(b) Honneth (2003b) observa que é possível de tratar-se de progresso moral, no caso de mudanças de limites entre as esferas de reconhecimento, quando o passo parcial dado em direção a um novo princípio melhora duradouramente as condições sociais da formação da identidade pessoal dos membros de determinados grupos ou classes. Nesse sentido, o princípio do direito teria um potencial intrínseco para intervir corretivamente nas outras esferas com vistas a garantir as condições mínimas da identidade dos indivíduos. Os afetados podem apelar a ele quando as suas condições de autonomia individual não forem suficientemente protegidas nas outras esferas. Em que pese essa peculiaridade do direito, há, todavia, que se manter a diferença existente entre as esferas. Isso se deve ao fato de que, na sociedade moderna, as condições de autorrealização individual somente estarão socialmente garantidas quando os sujeitos puderem experimentar não apenas 0 reconhecimento intersubjetivo de sua autonomia pessoal, mas também de suas necessidades e de suas capacidades particulares, conforme assegurado pelas outras esferas de reconhecimento.

Honneth constata que elaborar uma teoria social sólida, no plano normativo, implica não apenas procurar aplicar princípios normativos a uma ordem social em vista de melhorias moralmente justificadas, mas, sobretudo, descrever a realidade social de modo a mostrar como é possível tais princípios e normas tornaremse socialmente válidos. Nesse sentido, "as descrições da realidade social devem incluir sempre uma dimensão categorial que possa ser entendida como a encarnação de experiências e reflexões morais do mesmo modo que, inversamente, só podemos invocar normas e princípios que já se refletem de alguma maneira na ordem institucional da sociedade" (Honneth, 2003c, p.257). Nesse particular, o autor toma como referência, para a sua teoria normativa, a infraestrutura da sociedade moderna, permeada por expectativas de reconhecimento, e a ideia de um excedente de validez intrínseco a cada esfera de reconhecimento.

0 conceito normativo de excedente de validez é, pois, uma das chaves para a sustentação da ideia de progresso moral e a condição desta é que os princípios do reconhecimento abriguem sempre um potencial de realização de novas reivindicações morais de reconhecimento nos planos individual e social. É nesse sentido que as reivindicações morais podem colocar demandas mais exigentes que aquelas já realizadas no âmbito da realidade social existente. Tomando como referência essa ideia de progresso moral, pode-se constatar que as sociedades modernas passaram por processos normativos de desenvolvimento mediante os quais os princípios do amor interpessoal, da igualdade e do êxito foram enriquecendo-se sob a pressão de argumentos baseados na experiência. Por sua vez, esses enriquecimentos, que expandem normativamente os três princípios 
de reconhecimento, podem ser interpretados como indicadores de progresso moral. Isso ocorre na medida em que podem sinalizar na direção de processos de transformação social (Honneth, 2003c, p. 263). É por essa razão, por exemplo, que a forma moderna de integração social, configurada pelo princípio da igualdade, é uma ordem de reconhecimento moralmente superior a qualquer outra forma de reconhecimento existente nas sociedades tradicionais.

\section{A formação humana entre progresso moral e contradições (evoluções) paradoxais}

Viu-se até aqui que a sociedade moderna é concebida honnethianamente como resultado de um processo de diferenciação das esferas de reconhecimento - amor, direito e estima social - e de seus princípios - amor, igualdade e êxito - e que a tal processo pode ser vinculada uma ideia de progresso moral. Sob um ponto de vista normativo, essa concepção de progresso moral é possibilitada, sobretudo, pelo fato de que cada uma das esferas comporta um excedente de validez que proporciona o desenvolvimento de potenciais internos capazes de levar a novos desenvolvimentos no plano individual e social. Viu-se também que, para Honneth, o progresso moral caracteriza-se como uma ampliação no âmbito do reconhecimento mediante a socialização dos sujeitos e da inclusão social. Tratase, agora, de se extrair algumas consequências do percurso feito até aqui para o âmbito da formação humana. Isso será feito, contudo, estabelecendo um contraste entre a ideia de progresso moral e o conceito de contradição paradoxal (Honneth e Hartmann, 2006c) uma vez que, enquanto teoria social crítica que é, a teoria do reconhecimento situa-se sob o prisma de uma dialética da razão. Nesse aspecto, a ideia de progresso moral expressa como contraponto o diagnóstico do déficit de racionalidade que permeia as sociedades modernas e que lesa as condições de autorrealização dos sujeitos. Esse déficit possui, como sua feição atual mais marcante, o caráter de evolução paradoxal.

Honneth, juntamente com Hartmann (2006c), julga que as últimas décadas do século XX foram marcadas pelo avanço significativo de potenciais normativos e de reivindicações de reconhecimento que permitiram uma ampliação da institucionalização das esferas de reconhecimento e da integração em diferentes esferas normativas de ação. Essas mudanças socioculturais, assim como a multiplicação das relações sociais e o delineamento dos percursos biográficos, influenciaram de modo significativo a formação da identidade individual. Nesse sentido, especialmente, no último quarto do século $X X$, houve uma grande multiplicação das aspirações à realização individual, o que acelerou o processo de individuação inaugurado pela modernidade. Trata-se, conforme referido antes, de um significativo aumento das possibilidades de autorrealização no âmbito do 
processo de individuação e da intensificação do ideal de autenticidade gestado no final século XVIII. ${ }^{6}$ Esse aumento gerou efeitos significativos sobre tal processo dando origem a uma forma de individualismo orientado por um novo princípio de desenvolvimento de si, o individualismo da autorrealização. Para Honneth e Hartmann (2006c), contribuiu, para tal, a diversificação dos itinerários biográficos, os avanços no campo da educação, a expansão do tempo livre e a multiplicação das práticas de consumo. Em suma, trata-se de avanços normativos ocorridos no mundo contemporâneo que podem ser situados sob a súmula geral de progresso moral.

No entanto, ao mesmo tempo em que tais potenciais normativos avançam, desdobram-se as profundas transformações ocorridas no capitalismo contemporâneo que têm como efeito inverter tais ideais, impondo-se aos sujeitos com novas exigências. Decorre daí a modificação parcial do princípio de desenvolvimento de si em coações que resultam em novas formas de sofrimento e de patologias sociais. A juízo de Honneth e Hartmann (2006c), as transformações que ocorreram, nas últimas décadas, nas sociedades ocidentais, podem ser entendidas, por um lado, como progressos normativos que ampliaram as possibilidades de autorrealização para os sujeitos humanos; por outro lado, porém, são interpretadas como processos que induzem a novas coações que impedem a expansão de formas de autorrealização. Os autores procuram examinar as transformações ocorridas no capitalismo atual substituindo o velho modelo de contradições pelo de contradição (evolução) paradoxal e justificam tal opção com base no fato de que muitos dos progressos normativos que ocorreram em décadas passadas - particularmente, sob a égide do estado de bem estar social - foram revertidos pela forma neoliberal do capitalismo. Honneth e Hartmann observam que o termo paradoxo refere-se a um tipo específico de contradição, qual seja, aquela que ocorre quando, “...através da realização pretendida de um propósito, reduz-se simultaneamente a probabilidade de realizá-lo" (2006c, p. 286-7). Dessa posição, decorre que evoluções normativas que se configuram como progresso moral podem ser travestidas nos moldes de evoluções paradoxais, como no caso da transformação contemporânea do trabalhador em empresário de si mesmo. (Honneth, 2006b)

A questão central a ser colocada, então, é como as contradições paradoxais afetam os dois princípios que estão na base da ideia honnethiana de progresso moral - socialização e inclusão social - e como incidem sobre a formação da identidade dos sujeitos. Num sentido oposto, ela poderia ser posta da seguinte forma: Se as potencialidades de emancipação devem ser encontradas inscritas já na própria ordem social vigente - e isso é possível mediante a ideia normativa de progresso moral -, como elas poderiam superar as contradições paradoxais e fornecer indicativos para a formação da identidade humana de modo livre

\section{Sobre o advento do ideal de autenticidade ver, entre outros, Taylor (1994, p. 64-5).}


e autônomo? Na sequência, essa pergunta ocupa a reflexão tomando como fio condutor os três princípios do reconhecimento tematizados por Honneth e utilizar-se-á, como estratégia argumentativa, o contraste entre progresso moral e contradições paradoxais.

(a) No âmbito do princípio do amor, pode-se observar uma ampliação das possibilidades do desenvolvimento de individuação na medida em que essa é expandida para a maioria da população e ocorre a intensificação do ideal de autenticidade (Honneth; Hartmann, 2006c). Retrato de tal expansão é a ideia surgida no limite do século XIX do amor romântico como forma de opor-se ao mundo instrumental das relações de troca mercantilizadas, ou seja, à esfera fria das relações econômicas ou de casamentos arranjados para manter as posses ou o status das famílias. Os sujeitos conseguiam ali conservar os seus sentimentos relativamente livres de instrumentalização, protegendo as suas relações afetivas. Entretanto, a partir do século XX, ocorreu, gradativamente, a tendência a um processo de objetificação e comercialização do amor na medida em que os sujeitos recorrem, cada vez mais, a artigos de consumo para exprimir simbolicamente as suas relações afetivas e delimitá-las de forma ritualística diante do meio social.

Outro aspecto relacionado a essas transformações decorre das mudanças geradas no mundo do trabalho, fazendo com que as relações amorosas e íntimas de longo prazo fiquem expostas a uma carga elevada. Ocorre que a mobilidade dos sujeitos - flexíveis e disponíveis integralmente ao trabalho e à carreira - e as exigências de curto prazo dificultam relações de longo prazo. 0 novo espírito do capitalismo (Boltanski; Chiapello, 1999) transmite a ideia empresarial do agir calculador na relação dos sujeitos consigo próprios e esta parece penetrar até o âmago das relações íntimas na medida em que, nelas, começa a predominar um padrão de cálculo orientado pela utilidade. Permanece, aqui, a questão acerca do ideal amoroso de autenticidade e o tipo de exigências que o capitalismo contemporâneo coloca para a configuração da subjetividade como sujeito flexível, móbil etc. Como é possível a esse sujeito pensar um projeto de vida que vincule outra ou outras pessoas? Como é possível pensar processos formativos sem a perspectiva biográfica de médio e longo prazo?

b) Na esfera do princípio da igualdade, há uma ampliação da ideia de justiça, que se traduz como expansão de novos direitos sociais e de liberdade, o que permite melhorar as condições econômicas e sociais para o desenvolvimento individual da autonomia. Na era do estado de bem-estar social, a institucionalização dos direitos de status social mostrou que esses só são efetivados quando existem condições para a sua real materialização ou efetivação. Na era do capitalismo neoliberal, os direitos são convertidos em serviços, cujo uso depende dos recursos de quem os necessita. Os direitos mantêm-se formalmente vigentes, mas o seu acesso efetivo é privatizado. Há o advento de um discurso da responsabilidade própria que não explicita o fato de que a responsabilidade individual depende de condições internas e externas que precisam estar dadas para que os sujeitos possam ser 
considerados legitimamente responsáveis por seu agir ou por suas omissões. (Honneth; Hartmann, 2006c, p. 295)

Quando essas condições não são levadas em conta, a responsabilidade transforma-se num imperativo paradoxal, pois os sujeitos - em sociedades cada vez mais complexas - têm de assumir responsabilidades por circunstâncias pelas quais não são efetivamente responsáveis. Para os sujeitos, as consequências desse tipo de exigência refletem-se tanto como pressão para responsabilizar-se pelas coisas quanto na forma de responsabilidade psíquica pelas suas condições de vida. No plano educativo, tem-se, como decorrência, a transformação da educação em serviço (indústria educacional) ou mercadoria ${ }^{7}$ e a substituição da ideia de formação pela de carreira profissional.

(c) Por fim, no âmbito do princípio de desempenho (Leistung), há a emergência do status social de acordo com as capacidades e as contribuições do sujeito à sociedade. 0 princípio do desempenho é expandido, entre outros aspectos, mediante o movimento feminista, as reformas das políticas educativas e a liberação das relações íntimas relativamente às imposições externas de caráter social ou econômico, de modo que elas passam a ser contraídas por razões afetivas, mas não mais apenas em função dos filhos e da segurança vitalícia. 0 princípio de desempenho aparece na modernidade com um conteúdo emancipador e, em razão disso, as posições de status social passam a ser vinculadas ao trabalho. Isso aumenta o peso do princípio de desempenho dado que ninguém pode ser excluído dos esforços associados a ele por motivos de nascimento ou origem (Honneth; Hartmann, 2006c, p. 297). O sentido emancipador de tal princípio aparece, sobretudo, com base na ideia de que quanto maior for o âmbito em que o sujeito pode ter êxito mediante o seu esforço próprio, maior é a esfera de participação com chances iguais em posições de status social.

A sua origem está no princípio do individualismo do século XIX que ressalta o aspecto da autenticidade ou da singularidade de cada indivíduo: o ser você mesmo e contribuir com a sociedade a partir de suas capacidades e propriedades singulares. Trata-se de toda contribuição relevante e reconhecida como legítima dada pelo indivíduo à sociedade, seja como trabalho, arte, serviço social, esporte etc. 0 desempenho não se reduz apenas a critérios de produtividade, pois traduz o sentido de reconhecimento social. Com o capitalismo neoliberal, o princípio de desempenho transforma-se num meio que serve tanto para solapar os aspectos de bem estar social liberados do desempenho, como para participar do status onde essa possibilidade não existe. A insegurança gerada em relação ao valor e ao status do desempenho próprio é intensificada pelas características do capitalismo de projetos. $^{8}$ Sob a sua égide, torna-se difícil para o sujeito ter clareza sobre o valor verdadeiro de suas contribuições e resultados à sociedade.

7. A esse respeito, vide Dalbosco (2010) e Muhl (2009).

8. A esse respeito, vide Boltanski e Chiapello (1999). 
0 princípio do desempenho, sob a perspectiva neoliberal, coloca em questão o próprio ideal de autenticidade gestado nos séculos XVIII e XIX. Como reconhecerse nas contribuições pessoais dadas à sociedade quando esta subtrai as bases para ser efetivamente si próprio e cultivar o seu eu como de modo autônomo e individuado?

\section{Considerações finais}

0 percurso visou a explorar a concepção de progresso moral presente na teoria do reconhecimento honnethiana, situando-a a partir de sua concepção de modernidade para extrair alguns aportes à ideia de formação humana. A nosso ver, a produtividade dessa ideia para o campo educativo pode ser encontrada na possibilidade de ampliação, em sentido normativo, tanto da autorrelação prática do sujeito quanto das esferas sociais de reconhecimento. ${ }^{9}$ Todavia, procurouse mostrar que, como teoria social crítica que é, a teoria do reconhecimento honnethiana situa-se sob o prisma de uma dialética da razão. Se uma das faces da racionalidade moderna é impulsionadora de progresso moral, e isso pode ser claramente percebido mediante a diferenciação das esferas de reconhecimento e pelo excedente de validez contido nelas, o que permite avanços normativos consideráveis, a outra face pode ser identificada, na atual fase do capitalismo, na forma de evoluções paradoxais.

Viu-se que uma das condições colocadas por Honneth para o progresso moral das instituições e sociedades e, pois, para a ampliação das relações de reconhecimento, é a criação de condições para o desenvolvimento do excedente de validez contido em cada esfera de reconhecimento. Tal desenvolvimento pode ampliar os espaços de formação da subjetividade nas instituições sociais e, por conseguinte, também nas instituições educativas. Nesse sentido, por um lado, a ideia de progresso moral tem a ver com a capacidade do sujeito de expandirse mediante sua autorrelação prática e, por outro, está relacionada à ampliação dos espaços de liberdade e do potencial de racionalidade existente dentro das instituições.

Tal ideia pode impulsionar as instituições educativas a práticas emancipatórias levando-se em conta as três esferas de reconhecimento recíproco. No que concerne à esfera amorosa, isso se traduz no respeito às necessidades e singularidades, bem como na garantia do desenvolvimento e da ampliação da autoconfiança, base para todo o desenvolvimento e participação na vida social posterior. Podese referir, como exemplo de ampliação dessa esfera, à criação de mecanismos

9. Embora não tenha sido o objeto específico de estudo, isso implica considerar o papel que as instituições desempenham tanto para a realização quanto para a negação do reconhecimento recíproco. A esse respeito ver, por exemplo, Honneth (2006b), 
apropriados para fazer frente à violência em todas as suas formas de expressão no meio educativo formal. Na esfera jurídico-moral, pode-se pensar na ampliação de práticas formativas orientadas para a igual dignidade e a autonomia moral dos sujeitos. Por fim, no que tange à esfera social, poder-se-ia considerar a contribuição que as instituições educativas têm a oferecer para a ampliação da compreensão dos educandos sobre o sentido de fazer parte e contribuir com a sociedade mediante o exercício das próprias capacidades.

0 desenvolvimento de processos formativos orientado pelos princípios do reconhecimento recíproco pode ajudar, pois, a fazer frente aos reflexos das contradições ou evoluções paradoxais que repercutem dentro das instituições educativas. Tais contradições afetam, de diferentes maneiras, os princípios do reconhecimento em tais instituições e, embora não os eclipsem, precisam ser levadas em conta uma vez que afetam o processo de formação da subjetividade dos educandos. Nesse sentido, os princípios de socialização e de inclusão podem auxiliar a mostrar a importância de um adequado processo de individuação e da inclusão dos sujeitos como membros plenos da sociedade. Eles podem desempenhar um papel importante para impulsionar a formação humana calcada no reconhecimento e para dar passos na direção de uma teoria crítica da educação mediante o reconhecimento. Se, pois, por um lado, a questão central que orientou foi como as contradições paradoxais afetam a formação humana, inibindo os potenciais de progresso moral contidos em cada princípio e esfera do reconhecimento, por outro lado, pode-se postular que a ideia de formação humana e de progresso moral no contexto das sociedades complexas contemporâneas passa pela efetivação de tais princípios.

\section{Referências}

BOLTANSKI, Luc; CHIAPELLO, Eve. Le nouvel esprit du capitalisme. Paris: Gallimard, 1999.

DALBOSCO, Cláudio Almir. Pragmatismo, teoria crítica e educação. Campinas: Autores Associados, 2010.

HABERMAS, Jürgen. Para a reconstrução do materialismo histórico. 2ed. São Paulo: Brasilense, 1990.

HONNETH, Axel. Luta por reconhecimento: a gramática moral dos conflitos sociais. São Paulo: Editora 34, 2003.

. Redistribution as recognition: a response to Nancy Fraser. In: FRASER, Nancy; HONNETH, Axel. Redistribution or Recognition. Londres/Nova York: Verso, 2003b. p. 110-197.

The point of recognition: a rejoinder to the rejoinder. In: FRASER, Nancy; HONNETH, Axel. Redistribution or Recognition. Londres/NY: Verso, 2003c. p. 237-267. 
. Une pathologie sociale de la raison. Sur l'héritage intellectuel de la théorie critique. In: La societé du mépris. Paris: La découverte, 2006a (p.101-130). . La reconnaissance comme ideologie. In: La societé du mépris. Paris: La découverte, 2006b (p.245-274). .; HARTMANN, Martin. Les paradoxes du capitalisme: un programme de recherche. In: La societé du mépris. Paris: La découverte, 2006c (p.275-303).

Capitalisme et réalisation de soi: les paradoxes de l'individuation In: La societé du mépris. Paris: La découverte, 2006d (p.305-323).

2007.

Reificación: un estudio en la teoria del reconocimiento. Buenos Aires: Katz, . Das Recht der Freiheit, Berlin: Suhrkamp Verlag, 2011.

MUHL, Eldon Henrique. Cultura empresarial e formação docente. In: $\mathrm{CENCI}$, Angelo Vitório; FAVERO, Altair Alberto; TROMBETTA, Gerson Luis. Universidade, filosofia e cultura. Passo Fundo: UPF editora, 2009.

NOBRE, Marcos. Introdução. In: HONNETH, Axel. Luta por reconhecimento: a gramática moral dos conflitos sociais. São Paulo: Editora 34, 2003.

SGRÓ, Margarita. Educação pós-filosofia da história: racionalidade e emancipação. São Paulo: Cortez, 2007.

SIMMEL, Georg. Les grandes villes et la vie de l'esprit. Paris: L'Herne, 2007.

TAYLOR, Charles. Ética de la autenticidad. Barcelona: Paidós, 1994.

Recebido em março de 2013

Aprovado em maio de 2013

Angelo Vitório Cenci é professor do curso de filosofia e do programa de pós-graduação em educação da Universidade de Passo Fundo/RS. Email: angelođupf.br 